\title{
Evaluation of Secondary Acid and Enzymatic Hydrolysis of Hemicellulose in Hot Water Pre-Pulping Extract of Mixed Hardwoods*1
}

\author{
Byung-Hwan Um*2†
}

\begin{abstract}
Pre-pulping extracts were found to contain a dilute amount of xylo-oligosaccharides and acetic acid as the major components, and many minor components including other organic acids, lignin-derived phenolics, and sugar degradation products. Once separated from the pulp, a secondary hydrolysis step was required to hydrolyze oligomeric hemicellulose sugars into monomeric sugars before fermentation. The following study detailed the extent of hemicellulose recovery by pre-pulping using hot water extraction and characterized the hydrolysis of the extract with respect to comparing acid and enzymatic hydrolysis. The secondaryhydrolysis of hot water extracts made at an H-Factor of 800 was tested for a variety of acid and enzyme loading levels using the sulfuric acid and xylanases. The maximum fermentable sugar yield from acid and enzyme hydrolysis of the extract was $18.7 \mathrm{~g} / \ell$ and $17.7 \mathrm{~g} / \ell$ representing $84.6 \%$ and $80.1 \%$ of the maximum possible yield, respectively.
\end{abstract}

Keywords : acid hydrolysis, acetic acid, enzyme hydrolysis, hot water extraction, mixed hardwood, tubular reactor

\section{INTRODUCTION}

One promising development in conversion of lignocellulosic biomass to renewable fuels and chemicals is the process of pre-pulping hemicellulose extraction. Extracting hemicellulose prior to pulping creates a new feedstock within the existing pulp and paper industry while preserving cellulose for production of the more valuable pulp (van Heiningen, 2006). In present-day kraft pulp mills, hemicellulose is burned during chemical recovery along with lignin to generate power and steam (Smook, 2002). Because hemicellulose does not have a high heating value, conversion by biological fermentation processes offers a potential way to increase the value derived from lignocellulosic feedstocks within an integrated bio-refinery.

Fig. 1 presents the integrated pulp and biorefinery. To the chemical processing steps for producing value-added chemicals, it incorporatescomponents from existing biorefinerytype

*1 Received on March 5, 2012; accepted on March 24, 2012

*2 Departmentof Chemical Engineering, Hankyong National University, Anseong, Gyeonggi-do 456-749, Korea

† Corresponding author : Byung-Hwan Um (e-mail: bhum11@hknu.ac.kr) 


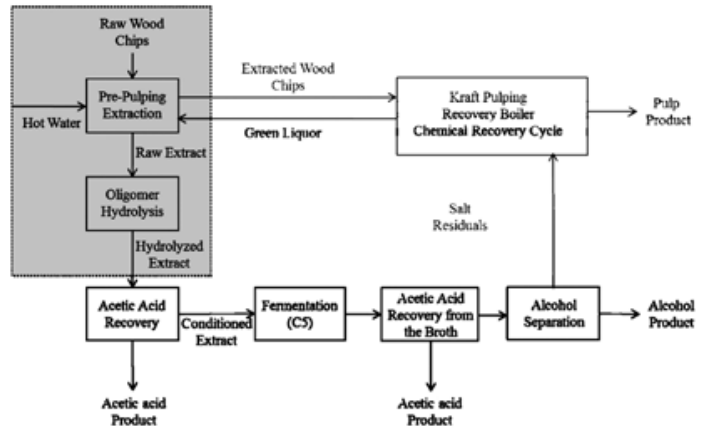

Fig 1. Simplified block diagram representing the process flow of a pulp and biorefinery. The pre-pulping extraction and oligomer hydrolysis steps are the focus of this study.

operations of wood pulp mill processes (Um et al., 2011; Huang et al., 2007). Carbohydrate separation and recovery involve both the fiveand six-carbon compounds, these compounds respond to separations by selective hydrolysis because they have different activities in either chemical or enzymatic hydrolyses. The lignin component, the least developed of the biomass fraction, is often viewed as a fuel to drive the processing systems, but it is also a potential source of aromatic chemical products (van Heiningen, 2006). In order to achieve a true biorefinery status, each biomass component would beused in the appropriate process to yield the highest value product. Therefore, a combination of processing steps, tailored to fit the particular operation, will be used to produce a slate of chemical products, which will be developed in response to the market drivers to optimize feedstock utilization and overall plant income. In this manner, the return on investment for converting low-cost feed stock to high-value chemical products can be maximized.

On an annual basis, the US pulp and paper industry sustainably collects and processes approximately 108 million tons of wood for the production of pulp and paper (Ragauskas et al.,
2006; Hekkert et al., 2001). Extractives from the pulping process provide approximately 700 million liters of turpentine and tall oil annually that could be employed for biodiesel applications (Ragauskas et al., 2006; Mabee, 2006). Hemicelluloses occur in relatively large amounts in hardwoods $(12 \sim 20 \%)$ and lesser amounts in softwoods $(3 \sim 8 \%)$ (Blanchette, 2000). They normally have monomeric substituents or, in some cases, branched oligomer chains, and vary in composition and structure. In the case of hardwoods, the hemicelluloses consist of linear chains of $\beta-1-4$ glycosidic bonded xylose monomers with an average degree of polymerization of 100 200 (Bailey and Ollis, 1986). Hemicellulose is a byproduct which is largely being wasted at pulp mills today. It is often burned in boilers with the lignin after the cellulose has been sorted out for pulp production. Recovery of hemicellulose sugars prior to the pulping operation reduces the mass of dissolved wood components and provides new product opportunities enhancing production of Kraft pulps. Extraction of hemicellulosic sugars by a hot water prehydrolysis produces sugars that are mostly oligosaccharides and small monosaccharides. Acetyl esters normally present on hemicellulose are partly cleaved, leaving some esters still attached to the sugars (Um, 2008; Kenealy et al., 2007). This complicates a detailed analysis of the sugars present and necessitates a secondary hydrolysis in the analysis of the total carbohydrates present. A second hydrolysis is even more important for the identification of the carbohydrate composition when the hemicellulose is extracted by an alkaline system. Here the hemicellulose comes out as a polymeric material and the acetyl esters as acetate. Polymeric oligosaccharides are easier to separate and concentrate from aqueous solutions by ultrafiltration and evaporation. Acetate could be recovered as a salt, but 
if acetic acid is the desired product then acid addition will be required. The separation of acetic acid and sugars can be accomplished with membrane filtration and has been proposed as a part of ethanol production from wood (Kenealy et al., 2007; Pu et al., 2007).

Advances are being made in the conversion and processing of lignocellulosic biomass to useful products. When the celluloseis converted to ethanol or other products the hemicellulose must also be used since it is a significant fraction of lignocellulosic materials. If cellulose is to be a significant portion of the product, as in paper, the hemicellulose and lignin are the only materials that can provide new products. In both cases, the processing and ultimate fate of the hemicellulose is important for the economics and design of the process. In this study, we investigated the optimal conditions of secondary acid and enzyme hydrolysis for maximum fermentable sugar recovery from hemicellulose extracts of mixed pulping wood. Furthermore, we characterize hydrolysis of the extract with respect to variable parameters and conclude with a comparison of acidic and enzymatic hydrolysis results.

\section{MATERIALS and METHODS}

\subsection{Raw Material}

Chips of mixed hardwood were supplied by the Red-Shield Kraft Pulp Mill in Old Town, ME, USA. The hardwood chips comprised primarily of maple $(\sim 50 \%)$ with lesser amounts of beech, birch and poplar. The chipswere screened to an average $7 / 8 \sim 5 / 8$ in $(22.6 \sim 16.0$ $\mathrm{mm}$ ) using a mechanically vibrated horizontal screen. The screened wood chips were used directly in hot water extraction studies. Some of the screened chips were ground to an average size of $30 \sim 40$ mesh $(0.595 \sim 0.420 \mathrm{~mm})$ using a laboratory knife mill. The milled wood chips were used directly for determination of total solids/moisture and carbohydrate content in biomass. The composition of this material was analyzed according to NREL laboratory analytical procedures: NREL/TP-510-42618 for Structural carbohydrates, TP-510-42623 for Sugars (Sluiter et al., 2008; Sluiter et al., 2006). The sugar composition of raw wood chips was $43.3 \%$ glucan, 2.6\% arabinan, 19.4\% XMG, and $23.1 \%$ Klason lignin. Here, XMG (capitalized) represents the sum total of the oligomeric sugar (xylan + mannan + galactan) and xmg (lowercase) represents monomeric sugar.

\subsection{Pre-Pulping Extraction}

The mixed northeast hardwood chips were used throughout this study. The hemicellulose extractions were performed using a $20 l$ rocking digester. The digester was loaded with $2 \mathrm{~kg}$ of chips of between 16 and $22.6 \mathrm{~mm}$ and cooked. An effective hot water on chips was used for all cases with liquor to wood ratio of $4: 1$. This system was agitated $(2 \mathrm{rpm})$ at $160^{\circ} \mathrm{C}$ for $110 \mathrm{~min}$ yielding an $\mathrm{H}$-factor 800 . The $\mathrm{H}$-factor is a kinetic model applicable to alkaline pulping that expresses cooking time and temperature as a single variable. The digester heat-up period lasted $50 \mathrm{~min}$ before steady state was reached, and cooled down after $110 \mathrm{~min}$. at operating temperature required an additional 50 min. Reactor pressure reached 130 psig during extraction. The reactor was then cooled below $100^{\circ} \mathrm{C}$. Samples were withdrawn and the total sugar and reducing sugar contents were quantified in the supernatant from the xylan suspension. Under extraction conditions approximately total $13.5 \%$ of the mass of the wood was extracted. 


\subsection{Secondary Acid Hydrolysis}

All batch acid hydrolysis experiments were performed using sealed tubular reactors. The vessel $\left(12 \mathrm{~cm}^{3}\right.$ of internal volume) was constructed out of stainless steel tubing because of its strength at elevated temperatures, and corrosion resistance. Both ends of the vessel were sealed with Swagelok end-caps into a size of 0.39 in. $(1 \mathrm{~cm})$ diameter $\times 5.91$ in. $(15 \mathrm{~cm})$ length. The acid hydrolysis was conducted with $10 \mathrm{~mL}$ hemicellulose extract under conditions ranging from 110 to $130^{\circ} \mathrm{C}, 0$ to $4 \% \mathrm{H}_{2} \mathrm{SO}_{4}$, and 20 - to $120-\mathrm{min}$ residence time. Temperatures of the vessel were adjusted with oil (Heat Transfer Fluid 550, Fisher, Pittsburgh, PA), which temperatures were controlled with external heating/cooling baths. The vessel was initially submerged into oil bath set at $50^{\circ} \mathrm{C}$ above the desired reaction temperature for rapid preheating. The vessel was then quickly transferred into next oil bath set at the precise desired reaction temperature. The vessel temperature was monitored by a thermocouple (KQXL18G-12, Omega Eng. Inc., Stamford, CT) inserted into the reactor. After finishing the reaction, the vessel was quenched in an ice bath for $10 \mathrm{~min}$.

\subsection{Secondary Enzyme Hydrolysis}

The xylo-oligosaccharide extracts were prepared for enzyme reaction by the previously described extraction process; the resulting solid concentration in the extract solution was $3.91 \%$. The experiments were conducted according to the NREL Laboratory Analytical Procedures (LAP): NREL/TP-510-42629 (Selig et al., 2008). The enzymatic hydrolyses were conducted with 3,000 U/g xylanase from Trichoderma viride (Xylanase 1, Fluka, distributed by Sigma- Aldrich, St. Louis, MO, USA) and 2,500 U/g xylanase from Thermo- myces lanuginosus (Xylanase 2, Sigma-Aldrich, St. Louis, MO, USA) under agitation (68 RPM) for $96 \mathrm{~h}$ at the temperatures of $40^{\circ} \mathrm{C}$. One unit (U) of each enzyme activity is defined as the amount of enzyme, which produces $1 \mu$ mol reducing sugar as $x y-$ lose in the reaction mixture per minute. Before adding the enzymes, the samples were placed in the shaker bath for $10 \mathrm{~min}$ to ensure thorough mixing and to warm the samples partially to the hydrolysis temperature. The enzymatic hydrolysis was conducted with $100 \mathrm{~m} \ell$ working volume under various conditions ranging from $\mathrm{pH}$ 1.5 to 6.0 in increments of one-half $\mathrm{pH}$ unit, and 0.5 to $4 \%$ enzyme. The $\mathrm{pH}$ was adjusted with $1 \mathrm{M} \mathrm{NaOH}$ or $\mathrm{HCl}$. These samples were then left to equilibrate for $30 \mathrm{~min}$, and then the $\mathrm{pH}$ was checked. In order to monitor the hydrolysis, samples were withdrawn and the reducing sugar contents and acetic acid were quantified by HPLC, after removal of the insoluble materials by centrifugation and syringe filtration.

\subsection{High Performance Liquid Chro- matography}

The sugar composition of reaction products was quantitatively analyzed by HPLC. The Shimadzu model (LC-10AT Liquid Chromatogram, Shimadzu Corp., Kyoto, Japan) HPLC used for carbohydrates measurement had BioRad Aminex HPX-87H (300 mm × 7.8 mm, Bio-Rad Laboratories Inc., Hercules, CA) and Cation $\mathrm{H}$ micro-guard cartridge $(30 \mathrm{~mm} \times 4.6$ $\mathrm{mm}$, Bio-Rad Laboratories Inc., Hercules, CA). The column was maintained at $60^{\circ} \mathrm{C}$, and $5 \mathrm{mM}$ $\mathrm{H}_{2} \mathrm{SO}_{4}$ was used for the Aminex $87 \mathrm{H}$-column as eluent at a flow rate of $0.6 \mathrm{~m} \ell / \mathrm{min}$. All of the sugar peaks were detected by a RI detector and UV absorption $(215 \mathrm{~nm})$ and were identified and quantified by comparison to retention times of authentic standards. The Bio-Rad Aminex HPX-87H analytical column allows the concur- 
Evaluation of Secondary Acid and Enzymatic Hydrolysis of Hemicellulose in Hot Water Pre-Pulping Extract of Mixed Hardwoods

Table 1. Analysis of raw extract composition used for experiments

\begin{tabular}{ccccccccc}
\hline & $\begin{array}{c}\text { Total Solid }^{\mathrm{a}} \\
{[\%]}\end{array}$ & $\mathrm{pH}$ & $\begin{array}{c}\text { Glucan } \\
{[\mathrm{g} / \ell]}\end{array}$ & $\begin{array}{c}\mathrm{XMG}^{\mathrm{b}} \\
{[\mathrm{g} / \ell]}\end{array}$ & $\begin{array}{c}\text { Arabinan } \\
{[\mathrm{g} / \ell]}\end{array}$ & $\begin{array}{c}\text { Acetyl } \\
{[\mathrm{g} / \ell]}\end{array}$ & $\begin{array}{c}\text { Furfural } \\
{[\mathrm{g} / \ell]}\end{array}$ & $\begin{array}{c}\text { Total Sugars }^{\mathrm{c}} \\
{[\mathrm{g} / \ell]}\end{array}$ \\
\hline \hline $\begin{array}{c}\text { Theoretical } \\
\text { Maximum Yield }\end{array}$ & & & 1.5 & 22.1 & 1.1 & 5.5 & 1.2 & 11.8 \\
$\begin{array}{c}\text { Untreated Blind } \\
\text { Control }^{\mathrm{e}}\end{array}$ & 3.91 & 3.55 & & & & & & 0.7 \\
\hline
\end{tabular}

${ }^{\mathrm{a}}$ Total solid fraction in the extracts after extraction

${ }^{\mathrm{b}} \mathrm{XMG}=$ xylan + mannan + galactan

${ }^{\mathrm{c}}$ Total sugars $=$ glucan $+\mathrm{XMG}+$ arabinan

${ }^{\mathrm{d}}$ Determination of initial sugar and acetyl concentrations were performed by acid hydrolysis, using NREL standard methods No.002, under conditions of $120^{\circ} \mathrm{C}, 4 \% \mathrm{H}_{2} \mathrm{SO}_{4}$, and 60 min residence time

${ }^{\mathrm{e}}$ No secondary acid hydrolysis
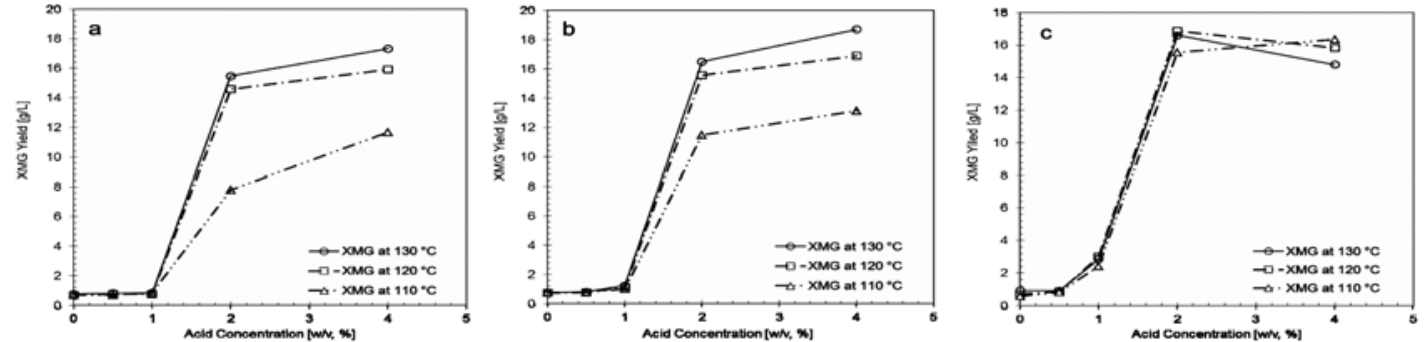

Fig 2. XMG yield from hot water pre-pulping extract of mixed northeast hardwood followed by secondary acid hydrolysis as function of temperature and acid concentration: reaction time (a) $20 \mathrm{~min}$ (b) $40 \mathrm{~min}$, and (c) $120 \mathrm{~min}$.

rent analysis of liquid sample for the presences of acetic acids and sugar degradation products.

\section{RESULTS and DISCUSSION}

\subsection{Pre-Pulping Extract}

The concentration of carbohydrates released from mixed hardwood chips following hot water extraction treatment is listed in Table 1. Total carbohydrates extracted represented 1.5, 22.1, and $1.1 \mathrm{~g} / \ell$ of glucan, XMG, and arabinan respectively. The ratio of glucan/XMG/arabinan mannose liberated from hemicellulose extract liquid was $0.07: 1: 0.05$. Analysis of these ratios implies that the XMG component is pre- dominantly derived from arabinoglucuronoxylan. Small amounts of glucan are likely the result of hydrolysis of galactoglucomannan. All process sugar yields from acid and enzymatic secondary hydrolysis were calculated from the basis of the sugar composition of extracts.

\subsection{Dilute-Acid Hydrolysis Results}

The main purpose of this part of the work was to investigate the influence of the known important reaction variables, temperature, time, and acid concentration. The effects of temperature (ranging from 110 to $130^{\circ} \mathrm{C}$ ) on dilute $\mathrm{H}_{2} \mathrm{SO}_{4}(0.5,2$, and $4 \mathrm{w} / \mathrm{v})$ hydrolysis of prepulping extract for various reaction time (20, 
40, and $129 \mathrm{~min}$ ) were evaluated. The data in Fig. 2 indicates that the XMG yields are dependent upon the reaction temperature as well as $\mathrm{H}_{2} \mathrm{SO}_{4}$ dose of secondary acid hydrolysis. The maximum yield of XMG was $18.7 \mathrm{~g} / \ell$ after dilute acid hydrolysis of $4 \% \mathrm{H}_{2} \mathrm{SO}_{4}(\mathrm{w} / \mathrm{v})$ extracted hemicellulose liquor for $40 \mathrm{~min}$ at $130^{\circ}$ C. (Fig. 2(b)). The acetate formation appears to peak at a temperature of $130^{\circ} \mathrm{C}$. Furfural, the decomposition of xylose, increased with the temperature (data not shown). This clearly indicates that pentose sugars (xylose and arabinose) derived from hemicellulose were further degraded. But, no HMF was produced per liter of extract. One reason is that small amounts of glucose are relatively extracted from hot water extraction process in the pre-pulping extract. The data on these minor constituents are, however, subject to little errors because their quantities are so small.

Pre-pulping extracts used in this study theoretically contained $1.5 \mathrm{~g} / \ell$ glucan, $22.1 \mathrm{~g} / \ell$ $\mathrm{XMG}$ and $1.1 \mathrm{~g} / \ell$ arabinan, which make up the total carbohydrate content of $24.7 \mathrm{~g} / \ell$ (Table 1). To reduce further degradation of monosaccharide formed, we have evaluated the effects of various acid doses on dilute $\mathrm{H}_{2} \mathrm{SO}_{4}$ hydrolysis. With 3.91\% (w/v, consistency) extracts, an acid dose of $4 \%(\mathrm{w} / \mathrm{v})$ gave maximum yield $(18.7 \mathrm{~g} / \ell)$ of fermentable sugars at $130^{\circ} \mathrm{C}$ (Fig. 2(b)). About $85 \%$ of hemicellulose was converted to sugars and only $50 \%$ glucan (data not shown) was converted to glucose. This trend in the results was similar to that reported for rapeseed straw (Jeong et al., 2010). Although the trends in the results were similar, the actual pentose sugar yields from the experiments were much higher than those collected by Jeong using rapeseed straw. The effect of the $0.5,1$, and $2 \%$ of $\mathrm{H}_{2} \mathrm{SO}_{4}$ dose on the hydrolysis was also studied. The maximum xylose sugars concentration present in the hydrolyzates were

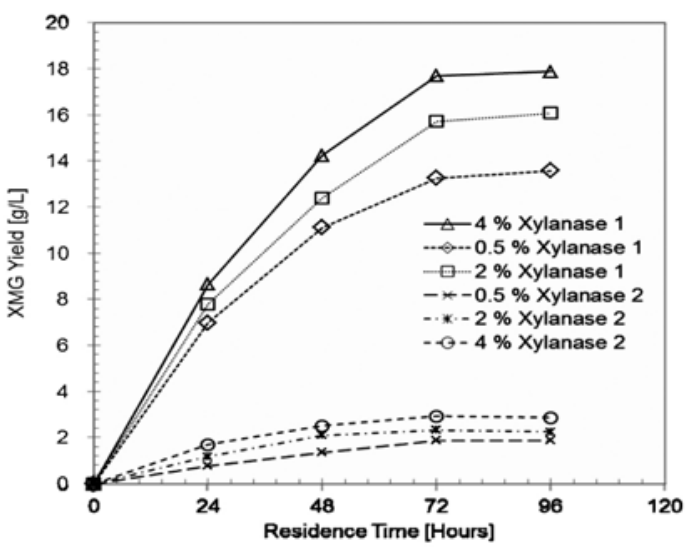

Fig 3. Effect of enzyme loading on XMGyield at constant temperature $\left(40^{\circ} \mathrm{C}\right)$.

$0.8,1.2$, and $16.5 \mathrm{~g} / \mathrm{l}$ with the acid doses of $0.5,1$, and $2 \%(\mathrm{w} / \mathrm{v})$ at the temperature of $130^{\circ} \mathrm{C}$, respectively.

The effect of residence time on various dilute $\mathrm{H}_{2} \mathrm{SO}_{4}$ hydrolysis of hemicellulose extract at the temperature ranged from 110 to $130^{\circ} \mathrm{C}$ was also studied (Fig. 2). Fig. 3 shows the XMG yield for $120 \mathrm{~min}$ reaction time as function of reaction temperature and acid concentration. The overall xylose yield did not increase with the increase of treatment time as a result of decrease in hemicellulose conversion (Fig. 3). Going to higher severity might somewhat reduce both the XMG remaining in the extract and the loss. Tested reaction times were selected such that the longest reaction time was sufficiently long to result in a decreased XMG yield, ensuring that a maximum yield had been at least bracketed by each experimental condition of temperature and acid concentration.

\subsection{Enzymatic Hydrolysis Results}

To explore various options for enzymatic conversion of the hemicellulose extract after hot water extraction process, we performed a series 
Evaluation of Secondary Acid and Enzymatic Hydrolysis of Hemicellulose in Hot Water Pre-Pulping Extract of Mixed Hardwoods

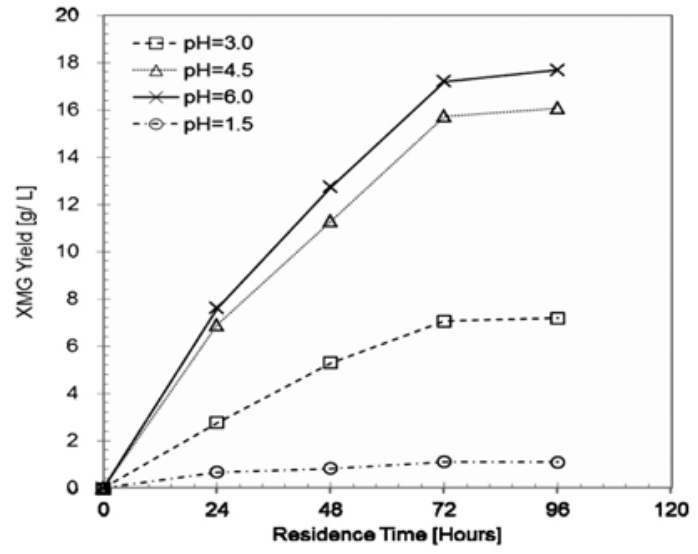

Fig 4. Enzymatic hydrolysis of pre-pulping extract for XMG yield as function of enzyme loading amount at constant temperature $\left(40^{\circ} \mathrm{C}\right)$.

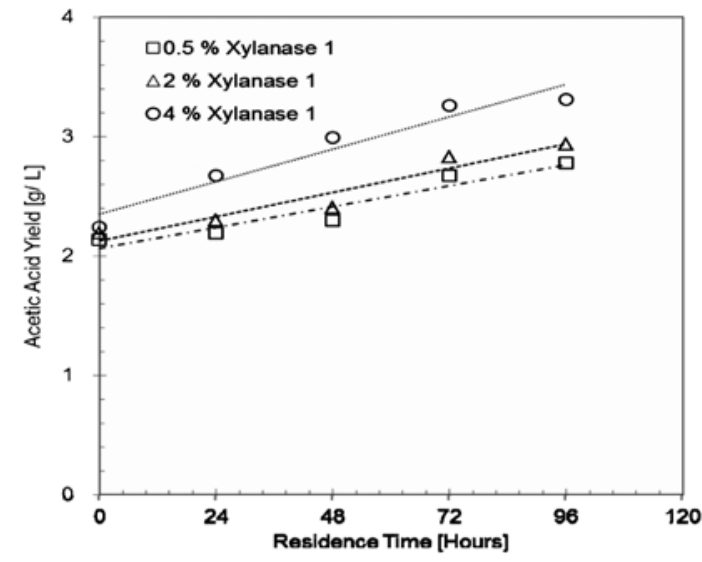

Fig 5. Acetic acid yield for different enzyme loading at constant temperature $\left(40^{\circ} \mathrm{C}\right)$.

Table 2. Comparison of different hydrolysis conditions at the highest xylose yield

\begin{tabular}{ccc}
\hline Conditions & Acid Hydrolysis & Enzyme Hydrolysis \\
\hline \hline Extracts & & $3.91 \%$ Total Solid \\
Temperature & $130^{\circ} \mathrm{C}$ & $40^{\circ} \mathrm{C}$ \\
Residence Time & $40 \mathrm{~min}$. & $72 \mathrm{hr}$. \\
Acid/Enzyme & $4 \%(\mathrm{w} / \mathrm{v})$ & $4 \%(\mathrm{w} / \mathrm{w})$ \\
Acid/Enzyme & Sulfuric Acid & Commercial Xylanase ${ }^{\mathrm{b}}$ \\
pH & 0.85 & 6.00 \\
$\mathrm{XMG}$ Yield & $18.7 \mathrm{~g} / \ell$ & $17.7 / \ell$ \\
XMG Digestibility & $84.6 \%$ & $80.1 \%$ \\
Temperature Controller & Oil bath & Convection Incubator \\
Reactor & Tubular Reactor & Erlenmeyer Flask \\
\hline
\end{tabular}

${ }^{a}$ Sulfuric Acid: Pure $96.00 \%$ (+/- 0.15\% solution in water).

${ }^{b}$ Xylanase: 3,000 U/g xylanase from Trichoderma viride.

${ }^{\mathrm{c}} \mathrm{XMG}=$ xylan + mannan + galactan

of enzymatic hydrolysis experiments to determine the effect of enzyme loading, $\mathrm{pH}$, and type of enzyme at a constant temperature. Fig. 3 presents the effect of different enzyme and enzyme loading on xylose yield from $3.91 \%$ con- sistency of extract as function of hydrolysis time at $40^{\circ} \mathrm{C}$. The range of xylanase loading, from 0.5 to $4 \%$, was selected for comparison with the xylose yield of the extract. The XMG yield of from the extract hydrolyzed by xyla- 
nase 1 (Trichoderma viride) was $17.7 \mathrm{~g} / \ell$ with a digestibility of $80.1 \%$ at $72 \mathrm{~h}$. Based on the amount of xmg released in a hydrolysis experiment, the yield of the total potential XMG in the extract solution increased with increasing the amount of enzyme loading. In the case of other xylanase 2 (Thermomyces lanuginosus), lower xmg was produced per liter of extract for the any enzyme loading at the temperature. From the XMG yield, it is seen that the activity of xylanase 1 (Trichoderma viride) was more stable for $72 \mathrm{~h}$ at $40^{\circ} \mathrm{C}$ than that of xylanase 2 (Thermomyces lanuginosus). Fig. 4 compares the XMG yield of the extract $(3.91 \%$ consistency) over a $\mathrm{pH}$ range of $1.5 \sim 6.0$ in increments of one-half $\mathrm{pH}$ unit. The slurry extract was adjusted with $\mathrm{NaOH}$ and $\mathrm{HCl}$ followed by leaving to equilibrate for $30 \mathrm{~min}$, and then the $\mathrm{pH}$ was checked. As a result, the enzymatic $\mathrm{XMG}$ yield is $17.2 \mathrm{~g} / \ell$ for the $\mathrm{pH}=6.0 \mathrm{sam}-$ ples and $15.7 \mathrm{~g} / \ell$ for the $\mathrm{pH}=4.5$ sample. The digestibility of these $\mathrm{pH}$ was $80.4 \%(\mathrm{pH}=$ $6.0)$ and $71.7 \%(\mathrm{pH}=4.5)$ respectively. Meanwhile, the acidic hydrolysis $(\mathrm{pH}=3$ and 1.5) did not give good yield of XMG from the extract. From the comparison, the optimum $\mathrm{pH}$ for the enzyme activity, as determined under these hydrolysis conditions was found to occur between a $\mathrm{pH}$ of 4.5 and 6.0 for xylanase 1 (Trichoderma viride). However, this trend is similar to results obtained from sugarcane bagasse (Adsul et al., 2005) and hardwood (Umand vanWalsum, 2009; 2010). Both of these studies suggested that residual lignin and acetic acid presented in hydrolyzate may play an important part in attracting the hydrolysis enzymes to the surface of the biomass.

The time courses of acetic acid yield for the enzyme loading by the xylanase 1 from the extract is shown in Fig. 5. Unlike previous acid hydrolysis, the acetic acid concentration was linearly increased. The acetic acid is likely de- riving from further hydrolysis of components in the extract. The mode of inhibition of acetic acid on enzyme hydrolysis may be via reduction of the $\mathrm{pH}$ below the optimal range, resulting in a decrease in XMG yield. Meanwhile, no furfural was detected per liter of extract in all the enzyme experiments. It is evident that most of the hemicellulose was solubilized and degraded to component monosaccharides (xmg) without further degradation of monosaccharides to HMF or furfural at the mild hydrolysis conditions.

\section{CONCLUSION}

The low production rates resulted from the low extraction yield, which was limited to approximately $13.5 \%$ of the debarked wood massin the current design. This was done because of concerns over loss of pulp yield and the effect that the extraction process has on the wood pulping process. More ethanol and acetic acid could be produced provided more of the hemicelluloses in the wood were extracted while still maintaining the pulp yield. However, we are now concentrating our effort to hydrolyze and saccharify the extract in such a way as not to produce any decomposition products or minimize the formation of these fermentation inhibitors. The maximum fermentable sugar yield from acid and enzyme hydrolysis of the extract was 18.7 and $17.7 \mathrm{~g} / \ell$ representing $84.6 \%$ and $80.1 \%$ of the maximum possible yield, respectively. These results did prove to provide a useful means of trading off the hydrolysis effects of these two different reagents on total pentose sugar yields.

\section{REFERENCES}

1. Adsul, M. G., J. E. Ghule, H. Shaikh, R. Singh, K. B. Bastawde, D.V. Gokhale, and A. J. Varma. 
2005. Enzymatic hydrolysis of delignified bagasse polysaccharides. Carbohydrate Polymers 62: $6 \sim 10$.

2. Bailey, J. E. and D. F. Ollis. 1986. Biochemical Engineering Fundamentals, second ed., McGrawHill: New York.

3. Blanchette, R. A. 2000. A review of microbial deterioration found in archaeological wood from different environments. International Biodeterioration \& Biodegradation 46: 189 204.

4. Chum, H. L., D. K. Johnson, S. K. Black, and R. P. Overend. 1990. Pretreatment-Catalyst effects and the combined severity parameter. Appl. Biochem. Biotechnol. 24/25: $1 \sim 14$.

5. Hekkert, M. P., L. A. J. Joosten, and E. Worrell. 2001. Analysis of the paper and wood flow in The Netherlands. Resources, Conservation and Recycling 30: 29 48.

6. Huang, H. J., S. Ramaswamy, U. W. Tschirner, B. V. Ramaro. 2008. Review: A review of separation technologies in current and future biorefineries. Separation and Purification Tech- nology, 62: $1 \sim 121$.

7. Jacobs, A. and O. Dahlman. 2001. Characterization of the Molar Masses of Hemicelluloses from Wood and Pulps Employing Size Exclusion Chromatography and Matrix-Assisted Laser Desorption Ionization Time-of-Flight Mass Spectrometry. Bio-macromolecules 2,894 $\sim 905$.

8. Jeong, T. S., B. H. Um, J.S. Kim, and K. K. Oh. 2010. Optimizing Dilute Acid Pretreatment of Rapeseed Straw for Extraction of Hemicellulose. Appl. Biochem. Biotechnol. 161: 22 23.

9. Kenealy, C., E. Horn, M. Davis, R. Swaney, and C. Houtman. 2007. Vapor-phase diethyl oxalate pretreatment of wood chips: Part 2. Release of hemicellulosic carbohydrates. Holzforschung 61: $230 \sim 235$.

10. Kenealy, W. R., C. J. Houtman, J. Laplaza, T. W. Jeffries, and E. G. Horn. 2007. Pretreatments for Converting Wood into Paper and Chemicals. A.C.S. Symposium Series 954: 392 408.

11. Lu, X. B., Y. M. Zhang, J. Yang, and Y. Liang. 2007. Enzymatic hydrolysis of corn stover after pretreatment with dilute sulfuric acid. Chem Eng Technol. 30(7): 938 944.

12. Mabee, W. 2006. Report: Economic, Environ- mental and Social Benefits of $2^{\text {nd }}$-Generation Biofuel In Canada.

13. Pu, Y., D. C. Zhang, P. M. Singh, and A. J. Ragauskas. 2007. The new forestry biofuels sector. Biofuels, Bioproducts and Biorefining 2: $58 \sim 73$.

14. Ragauskas, A. J., M. Nagy, D. H. Kim, C. A. Eckert, J. P. Hallett, and C. L. Liotta. 2006. From wood to fuels: Integrating biofuels and pulp production. Industrial Biotechnology 2: 55 $\sim 65$.

15. Sluiter, A., B. Hames, R. Ruiz, C. Scarlata, J. Sluiter, and D. Tmpleton. 2008. Determination of structural carbohydrates and lignin in biomass. National Renewable Energy Laboratory NREL/ TP-510-42618 ed. Golden, CO.

16. Sluiter, A., B. Hames, R. Ruiz, C. Scarlata, J. Sluiter, and D. Tmpleton. 2006. Determination of sugars, yproducts, and degradation products in liquid fraction process samples. National Renewable Energy Laboratory NREL/TP-510-426 23 ed. Golden, CO.

17. Smook, G. 2002. Handbook for Pulp \& Paper Technologists, $3^{\text {rd }}$ ed. Angus Wilde Publications, Inc., Vancouver, B.C.

18. Selig, M., N. Wessi, and Y. Ji. 2008. Enzymatic saccharification of lignicellulosic biomass. National Renewable Energy Laboratory NREL/ TP510-42629 ed. Golden, CO.

19. Tengborg, C., K. Stenberg, M. Galbe, G. Zacchi, S. Larsson, E. Palmqvist, and B. Hahn-Hägerdal. 1998. Comparison of $\mathrm{SO}_{2}$ and $\mathrm{H}_{2} \mathrm{SO}_{4}$ Impregnation of Softwood Prior to Steam Pretreatment on Ethanol Production. Appl. Biochem. Biotechnol. $70 \sim 72: 3 \sim 15$.

20. Um, B. H., B. Friedman, and G. P. van Walsum, 2011. Conditioning hardwood-derived pre-pulping extracts for use in fermentation through removal and recovery of acetic acid using trioctylphosphine oxide (TOPO). Holzforschung. 65: $51 \sim 58$.

21. Um, B. H. 2008. Rheological properties and particle size distribution of northeast mixed hardwood for enzymatic saccharification processing with high substrate loading. Mokchae Konghak. 36(5): $56 \sim 65$.

22. Um, B. H. and G. P. van Walsum. 2009. Acid 
Hydrolysis of Hemicellulose in Green Liquor Pre-Pulping Extract of Mixed Northern Hardwoods. Appl. Biochem. Biotechnol. 153: 127 138.

23. Um, B. H. and G. P. van Walsum. 2010. Evaluation of Enzyme Mixtures in Releasing
Fermentable Sugars from Pre-pulping Extracts of Mixed Northeast Hardwoods. Appl. Biochem. Biotechnol. 161: 432 447.

24. A. van Heiningen. 2006. Converting a kraft pulp mill into an integrated biorefinery. Pulp PapCanada. 107(6): 38 43. 